\title{
A survey on hybrid problem-based learning in a digital image processing course
}

Songxin Tan, Zixing Shen

Songxin Tan, Zixing Shen, "A survey on hybrid problem-based learning in a digital image processing course," Proc. SPIE 11143, Fifteenth Conference on Education and Training in Optics and Photonics: ETOP 2019, 111432Y (2 July 2019); doi: 10.1117/12.2521467

SPIE Event: Fifteenth Conference on Education and Training in Optics and Photonics: ETOP 2019, 2019, Quebec City, Quebec, Canada 


\title{
A survey on hybrid problem-based learning in a digital image processing course
}

\author{
Songxin Tan*a, Zixing Shen ${ }^{\mathrm{b}}$ \\ ${ }^{a}$ Department of EECS, South Dakota State University, Brookings, SD, USA 57007-2222; ${ }^{\text {b College }}$ \\ of Business and Information Systems, Dakota State University, Madison, SD, USA 57042-1799
}

\begin{abstract}
A hybrid problem-based learning (h-PBL) strategy was developed and executed in a digital image processing (DIP) course at the South Dakota State University. The newly developed curriculum encompasses the design and implementation of a problem-based learning (PBL) project: a three dimensional (3D) imaging project using fringe projection. The PBL project requires students to build a digital fringe projection system using a digital projector, to use a digital camera to capture the deformed fringe patterns projected onto the object under study, and to process the captured images using the software Matlab in order to retrieve the 3D profile of the object. The course was taught in a hybrid fashion with a mixture of both traditional lecturing (TL) and PBL, to replace the previous TL course. This paper presents the curriculum development activity and investigates the student perspectives on the developed h-PBL approach through a survey study. Longitudinal data from the open-ended surveys administered after the completion of the PBL project were collected from the multipleyear study of the DIP course taught by the same instructor. Data analysis reveals that a higher level of student satisfaction was achieved after h-PBL. The h-PBL approach, albeit more challenging and time-consuming in comparison with TL, motivated and stimulated student self-regulated learning, improved student problem solving skill, and promoted student critical thinking.
\end{abstract}

Keywords: Hybrid problem-based learning, active learning, digital image processing, profilometry, fringe projection

\section{INTRODUCTION}

Problem-based learning (PBL) has been a focused area of the pedagogical research for many years. It is regarded as one of the most significant pedagogical innovations in the history of higher education ${ }^{1}$. As an active leaning strategy, PBL places students at the center of the learning process, because the appropriation and assimilation of knowledge ultimately can only be done by the leaners, not the teachers. The fundamental idea of PBL education is that the students acquire knowledge and skills through the instructor-staged and curriculum-based problem or query, together with associated learning materials and support from instructors ${ }^{1}$. PBL started in the health science education as a way to train medical students in clinical studies ${ }^{2}$, and quickly spread to other education disciplines in natural science ${ }^{3}$, social science ${ }^{4}$, engineering ${ }^{5}$, and many other.

Under PBL, traditional lectures are either totally eliminated or reduced to give room for student self-directed learning. Students work in groups to solve challenging practical problem. The problem is curriculum-based and often is interdisciplinary in nature. Further, it is open-ended and targeted for current applications of the real-world problems. Hence, the problem is intentionally kept vague in description. Unlike traditional lecturing (TL), the instructor serves more as a facilitator in the classroom. The instructor provides generic guidance, but is not directly involved in the management and solution of the project. Under PBL, students take the initiative in the learning process. They learn to gather information, to synthesize and analyze information in order to gain knowledge. This learning process requires collaboration and reflection ${ }^{6}$. PBL emphasizes the active engagement of students in the learning process, as the renowned American educator John Dewey put it, "true learning is based on discovery guided by mentoring rather than the transmission of knowledge"7.

There have been a multitude of discussions on how to implement $\mathrm{PBL}^{6}$. In fact, PBL implementation was open-ended and flexible, which varies largely from case to case. Individual instructor aiming at implementing PBL should select or develop the appropriate PBL approach in order to achieve the specific educational objective. Broadly speaking, PBL can be categorized as either a pure PBL (or PBL) or a hybrid-PBL (h-PBL). The first PBL originated from medical education was

*songxin.tan@sdstate.edu; phone 1605 688-4994; fax 1605 688-4401; 
a pure PBL approach where traditional lectures were completely eliminated to give room to a problem-based learning, in this case, clinical practice based learning. Later, hybrid PBL was developed which incorporated the traditional lecturing features into the PBL course, in order to take advantages of both the structured traditional learning and the student-centered PBL learning.

A hybrid-PBL approach for the Digital Image Processing (DIP) course at the Department of EECS, South Dakota State University (SDSU), was developed and implemented. This new approach combined the traditional lectures with a PBL project. The developed PBL project was a 3D imaging project using digital fringe projection technique. The PBL project required students to build a digital fringe projection system using a digital projector, to use a digital camera to capture the deformed fringe patterns projected onto the object under study, and to process the captured images using the software Matlab in order to retrieve the 3D profile of the object. Our previous longitudinal study analyzed student performance by comparing student grades in TL and h-PBL from an eight-year study period ${ }^{6}$. It revealed that PBL improved student project grades and confirmed the positive effect of PBL. Furthermore, it also cautioned on the execution of h-PBL in terms of the project design, implementation, and assessment, and pointed out factors such as the project timing, the ratio between TL and PBL, and the integration of all course components could affect the effectiveness of h-PBL as measured by student performance data. It provided explanation for the student grade variability as observed in the previous literature that only some study reported grade improvement, and identified future research directions to maximize the educational benefit of PBL.

This paper will focus on the student perspective of PBL. We developed a survey in order to collect student feedback on PBL. Four-year survey data during the h-PBL period were collected and analyzed in this paper. Our Study supports that PBL benefits students learning and demonstrates that students are in favor of the h-PBL approach.

\section{COURSE BACKGROUND}

At SDSU, DIP is a technical elective course for under-graduate senior and first year graduate students. It is a three-credithour course offered once a year in every fall semester. The course prerequisite is Signals and Systems. Students are required to have basic programming skill (in either Matlab or $\mathrm{C}$ language) before taking this course.

The specific ABET student learning outcomes (SLOs) ${ }^{8}$ addressed in this course are to:

- demonstrate the ability to apply mathematics and linear system theory to engineering problems; (ABET outcome a)

- demonstrate the ability to identify, formulate and solve engineering problems; (ABET outcome e)

- demonstrate the ability to communicate effectively in both written and oral form; (ABET outcome g)

- understand the impact of engineering solutions in a global and societal context; (ABET outcome h)

- demonstrate the ability to engage in life-long learning; (ABET outcome i)

- gain knowledge in contemporary issues related to DIP; (ABET outcome j)

- demonstrate the ability to use software tools in DIP. (ABET outcome $\mathrm{k}$ )

This DIP course was taught using traditional lectures from 2005 to 2010. A decision was made to introduce hybrid PBL into the course; subsequently, the 3D imaging PBL project was developed. This approach was implemented from 2011 to 2014. The result presented in this paper covers the later four-year study period.

A hybrid-PBL approach was developed for the DIP course. The hybrid PBL model was considered to be less intrusive, and easier to integrate into the existing course curriculum. In addition, it may fit the student learning style and the overall student learning culture better at SDSU. It was decided that the h-PBL model should be implemented as a way to smoothly transit from TL to PBL. The potential student resistance to a more challenging PBL approach was a main concern at that time. In the h-PBL approach, traditional lectures were used in the first part of the semester. The TL components including essays, computer assignments, and exams. PBL project was assigned to students in the second half the semester. The detail of the PBL project is presented in the next section. However, it is worth emphasizing that the PBL project is not simply another course project. The PBL project has to be curriculum-based and open-ended, be able to stimulate student independent learning with minimum instructor intervention in solving the problem. Hence the technical scope and depth of the project has to be carefully examined in order to deliver the intended educational benefits. In our case study, the ratio of the time spend on TL versus on PBL was close to 4:1. In terms of student assessment, approximately $60 \%$ of the course grade was from the TL components and rest $40 \%$ was from the PBL project. Such an approach was developed partially in 
order to facilitate the comparative study of the TL approach that was done prior to the implementation of h-PBL approach by the same instructor. More details were presented in our previous publication ${ }^{6}$.

\section{THE PBL PROJECT}

While projects has been used in course teaching traditionally, the distinctions between a TL project and a PBL project are often not well recognized. Bout and Feletti ${ }^{1}$ pointed out that "while there are different versions of what constitutes PBL, it does not, as it sometime erroneously assumed, involve the tradition of problem-solving activities to otherwise discipline centered curricula." and there were "misapplications and misconceptions of PBL". At the center of the distinctions, PBL project has to be student-centered, inquiry-based, and curriculum-based. In a nutshell, PBL project has to be real-world project that has enough technical breadth and depth such that it initiates students' independent learning and challenges their critical thinking ability.

This developed 3D imaging project is a fringe project system ${ }^{9,10}$. The optical setup is illustrated in Figure 1. A manikin head was used as a measurement target in this illustration. Other simple geometric shapes such as triangle and sphere were also used. An Optoma EP 739 digital light processing (DLP) projector was used for fringe projection. The deformed pattern is described by

$$
I_{i}(x, y)=r(x, y)\left\{a(x, y)+b(x, y) \cos \left[2 \pi f_{0} x+\frac{2 \pi i}{N}+\varphi(x, y)\right]\right\}
$$

where $\mathrm{i}$ is an integer and $\mathrm{i}=0,1, \ldots, \mathrm{N}-1$ for $\mathrm{N}$-phase-shift. The term $a(x, y)$ describes the ambient illumination; $b(x, y)$ is the fringe contrast; $f_{0}$ is the fringe frequency; $\varphi(x, y)$ is the phase caused by the target 3D profile; and $r(x, y)$ is caused by the target reflectivity. For a flat reference plane, $\varphi(x, y)=0$. Ideally, a constant $r(x, y)$ is desired. However, in practice, $r(x, y)$ can exhibits spatial variation across the imaging plane, which leads to erroneous 3D reconstruction. Figure 2 shows one deformed fringe pattern image after fringe projection onto a manikin head. In this case, an area of shadow is clearly seen on the right side of the manikin head. Shadow area does not contain any fringe information and therefore is impossible to retrieve the height. However, because the shadow is on the reference plane behind the manikin in this case, the height can be either interpolated or extrapolated.

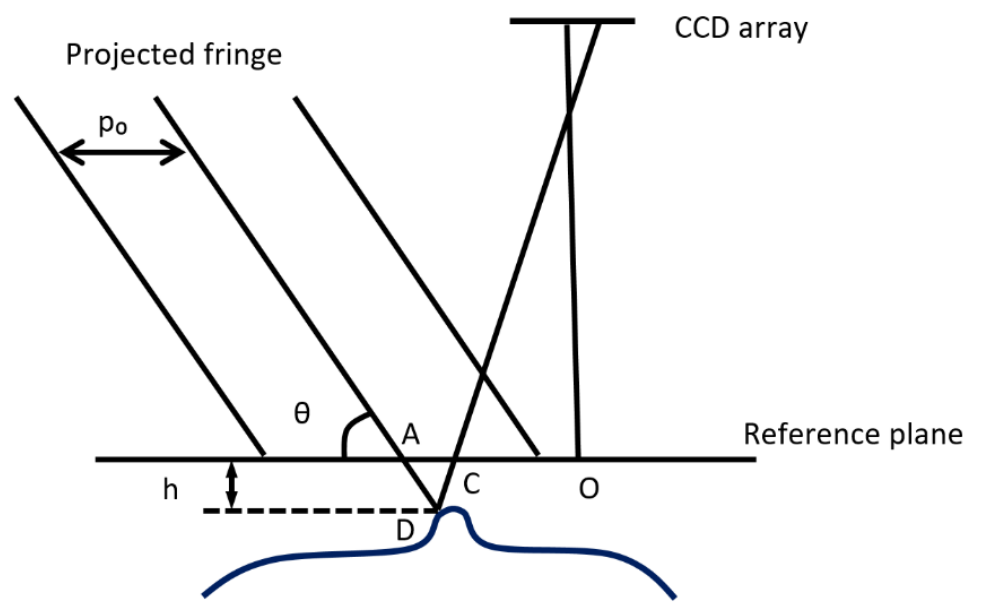

Figure 1 . The 3D imaging system configuration that is composed by the projector, the camera, and the target under study. The equivalent wavelength of the projected fringe viewed by the camera is noted as po, object height at point $\mathrm{D}$ is $\mathrm{h}$.

A Canon 350D Digital Rebel XT camera with a Canon EF 24-70 mm f/2.8L II USM lens was used for image acquiring. Due to the limited dynamic range of the digital projector and the camera, the acquired fringe pattern is often not perfect sinusoidal. This causes large error in the measured profile data, and needs to be corrected ${ }^{11}$. The acquired fringe images need noise reduction and Gamma correction in order to improve the measurement accuracy ${ }^{12}$. The phase of the deformed fringe pattern is directly associated with the target profile and is obtained by

$$
\phi(x, y)=\arctan \left\{\frac{\sum_{i=0}^{N-1} I_{i} \sin \left(\frac{2 \pi i}{N}\right)}{\sum_{i=0}^{N-1} I_{i} \cos \left(\frac{2 \pi i}{N}\right)}\right\} .
$$


Because the phase is obtained through arctangent function, the obtained phase $\phi(x, y)$ from Eq. (2) is limited within the range of $(-\pi, \pi)$, when considering the signs. We need to find the true or unwrapped phase $\varphi(x, y)$. This is called phase wrapping ${ }^{13}$. Phase unwrapping is one of the most challenging tasks in this project ${ }^{14}$. Generally, the unwrapped phase is obtained by

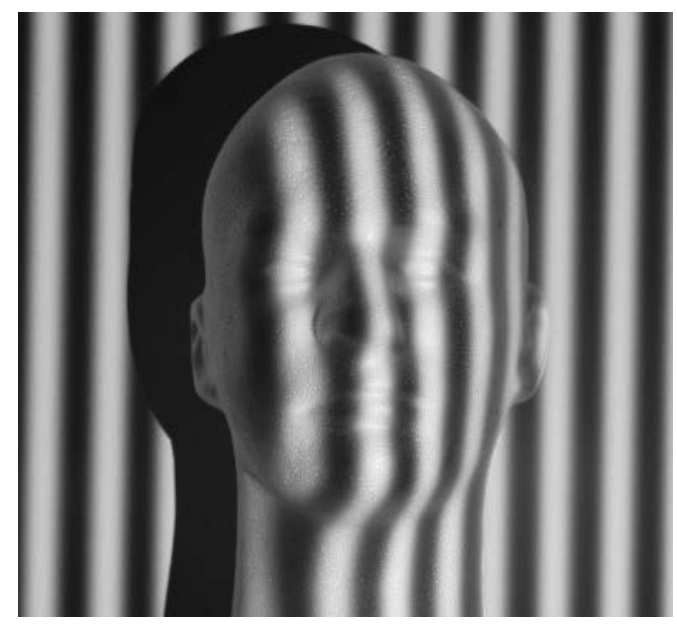

Figure 2. An example of the deformed fringe pattern from a manikin head target. Notice the shadow that does not have any fringe information, which can lead to erroneous phase unwrapping.

$$
\varphi(x, y)=\phi(x, y) \pm 2 n \pi,
$$

where $n$ is an integer. The process is to find all phase jumps that are greater than $\pi$ and then to eliminate the phase jumps by adding or subtracting $2 n \pi$, where $n$ is an integer that is determined by the phase unwrapping algorithm. However, abnormalities such as shadow (see Figure 2) and random noise cause poles ${ }^{15}$ in the phase map, and make this an ill-posed problem. Many efforts have been made toward more reliable phase unwrapping ${ }^{16}$.

Once the unwrapped phase map is obtained, the target 3D profile can be computed based on the geometry of the experimental setup, as demonstrated in Figure 1. The point $C$ on the reference plane as seen by the CCD camera would appear to be point $\mathrm{A}$ when the object is presented. If $p_{0}$ is the period of the projected fringe as seen on the reference plane, then the phase of point $\mathrm{C}$ is

$$
\varphi_{C}=2 \pi \frac{o C}{p_{0}} .
$$

And the phase at point $\mathrm{A}$ is

$$
\varphi_{A}=2 \pi \frac{O A}{p_{0}} .
$$

If the projected fringe has an angle $\theta$ with respect to the reference plane, as shown in Figure 1, then the phase $\phi(x, y)$ is:

$$
\varphi(x, y)=\varphi_{A}-\varphi_{c} .
$$

Therefore, the distance AC is:

$$
A C=\varphi(x, y) \frac{p_{0}}{2 \pi} .
$$

For a camera with large demagnification factor, CD is almost normal to the CCD array. Therefore, object height at point $\mathrm{D}$ is obtained by

$$
h=C D=A C \times \tan \theta .
$$

A block diagram illustrating the generic procedures of the 3D imaging project is shown in Figure 3. To illustrate the project final outcome, an example of the 3D reconstructed manikin head obtained by a student group during the h-PBL in the DIP course is demonstrated in Figure 4. The result is an example of a successful reconstruction of the manikin head with all facial features presented clearly. However, close inspection still reveals undulating surface, which is caused primarily by the Gamma distortion. 


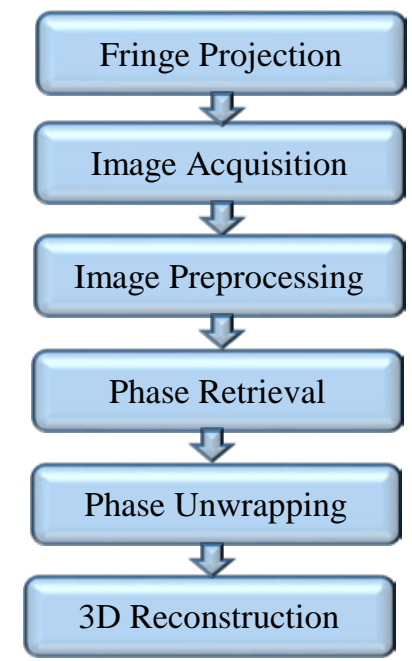

Figure 3. Block diagram illustrating the generic procedures of the 3D imaging project.

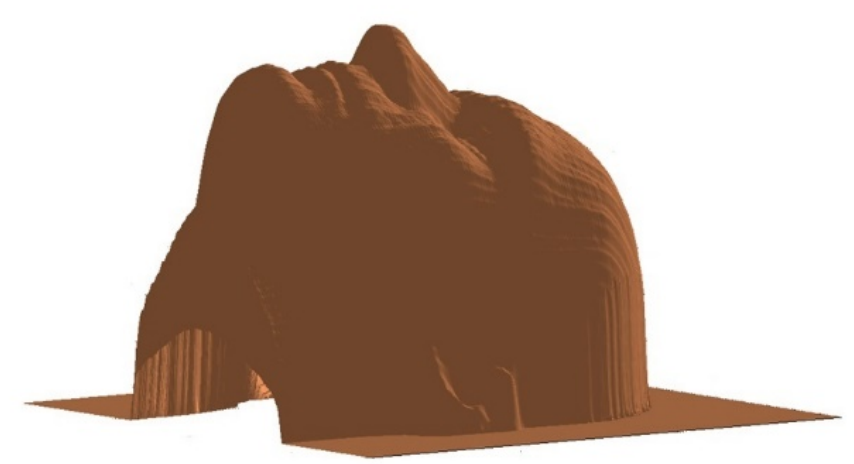

Figure 4. A reconstructed 3D manikin head by one student group.

\section{STUDENT SURVEY}

In this study, anonymous student surveys were administered during the h-PBL implementation period. Survey was used as an important tool to gauge the success of h-PBL from the perspective of the students. The surveys were done at the end of each semester, after the completion of the PBL project and before the final grades were released to the students. We developed eight survey questions, as listed in Table 1 . These questions were designed based on the previous PBL literatures in order to address some of the most prominent student concerns on PBL. In addition, one of the biggest concerns from the instructor was the level of student acceptance to PBL from a TL-dominant culture. In other word, would students be willing to accept PBL? If so, to what degree would they accept it? These are critical to the successful implementation of PBL.

In the developed survey, the Likert scale ${ }^{17}$ was used from Question 1 to 7 , where the quantity ' 1 ' was used to denote strongly disagree, and '2' for disagree, '3' for neutral, '4' for agree, '5' for strongly agree. Whereas, Question 8 was answered by providing a numerical value, i.e., the percentage of TL that the students would prefer in the hybrid PBL course. In addition, open space was provided at the end of the survey form to include student written comments regarding h-PBL. Four surveys were administered from 2011 to 2014 during h-PBL period. The number of students participating in the surveys is listed in Table 2. As shown, a total number of 41 students participated in the surveys. 
Table 1. List of the developed survey questions.

\begin{tabular}{|l|l|}
\hline Q1: & $\begin{array}{l}\text { How do you like the Problem Based Learning (PBL) approach } \\
\text { in this course? }\end{array}$ \\
\hline Q2: & $\begin{array}{l}\text { Compared with the traditional lecture (TL) approach, do you } \\
\text { feel that you learned more through the PBL approach? }\end{array}$ \\
\hline Q3: & Do you feel that PBL motivated you to learn? \\
\hline Q4: & $\begin{array}{l}\text { Do you think that PBL improved your independent learning } \\
\text { skill? }\end{array}$ \\
\hline Q5: & Do you feel that PBL is more difficult than TL? \\
\hline Q6: & $\begin{array}{l}\text { Do you feel that you need to make more effort to learn } \\
\text { under PBL? }\end{array}$ \\
\hline Q7: & $\begin{array}{l}\text { Would you like to have a course with PBL only and without } \\
\text { traditional lecture at all? }\end{array}$ \\
\hline Q8: & $\begin{array}{l}\text { If both TL and PBL are used in this course, what would be the } \\
\text { preferred percentage of TL for you? }\end{array}$ \\
\hline
\end{tabular}

Table 2. Number of students participated in the survey.

\begin{tabular}{|c|c|c|c|c|}
\hline Year & 2011 & 2012 & 2013 & 2014 \\
\hline \# of student & 15 & 11 & 8 & 7 \\
\hline
\end{tabular}

The four-year data were collected and analyzed. The average student response to the first seven questions (Q1 to Q7) over each year was plotted in Figure 5. In order to further examine the overall student response, the average response and the standard deviation value of the four-year data were calculated for each individual question from Q1 to Q7, and listed in Table 3.

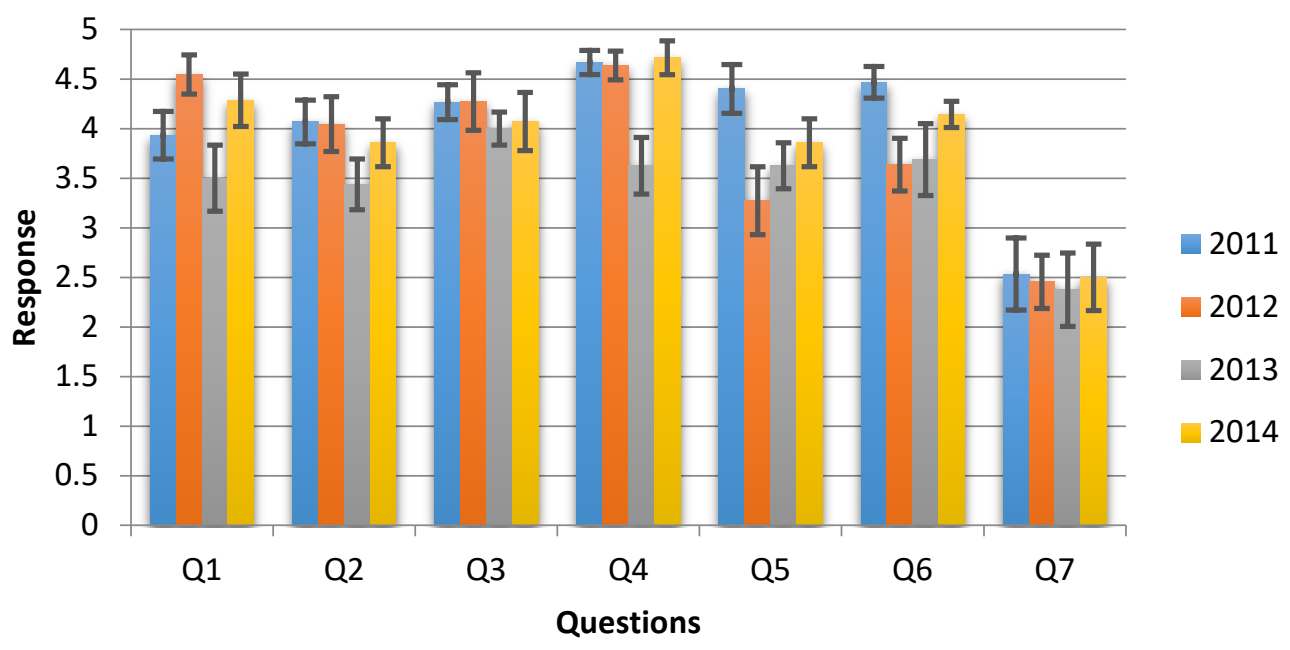

Figure 5. Average student response to the survey questions Q1 to Q7. The response was using Likert scale from 1 to 5 , where ' 1 ' is for the strongest disagree and ' 5 ' is for the strongest agree. The error bar marks the standard error.

The result, as seen from both Figure 5 and Table 3, reveals that Q4 has the highest average response values which exceed 4.0, indicating to a greater degree that the students were in very strong agreement that PBL improved their independent learning ability. Average responses to Q1, Q3 and Q6 are in between 3.83 and 3.96, which is close to 4.0. This suggests that students were in favor of the PBL approach, that they agreed that PBL motivated them to learn, and that indeed they needed to put in more efforts in the course learning. The responses to Q2 and Q5 are 3.70 and 3.66, demonstrating that they agreed PBL motivated them to learn, but also the learning is more difficult. Interestingly, survey result from Q7 suggests that our students were not in favor of the pure PBL approach. The average response over the four years is 2.39, 
indicting their opinions on pure PBL is between disagree and neutral. Written comments suggests that they were concerned about the technical challenges associated with pure PBL, and therefore, not sure if they could handle pure PBL without any lectures. Their preference was to have the h-PBL approach instead.

Furthermore, the overall standard deviation values, ranging between 1.10 and 1.20 , are relatively close. This indicates overall consistency in student perceptions toward these questions. Nevertheless, the standard deviation for Q5 is the highest (std=1.20), indicating a relatively wider disagreement among students in terms of the level of difficulty associated with PBL. Indeed, conversations with students revealed that these with higher GPA tended to show more confidence in dealing with the challenges associated with PBL in general. In addition, it is worth pointing out that the yearly average response is the most consistent on Q2 ( $\mathrm{std}=1.10$ ). This consistency in yearly data suggests less disparity on their perceptions regarding how much they learned from PBL. Moreover, careful examination of the data in Tab. 3 shows good agreement with Figure 5 in terms of the yearly differences from Q1 to Q7. However, the four-year data lead to generally consistent conclusions even though some slight variations are observed.

Table 3. The average and standard deviation of student response over the four-year h-PBL period.

\begin{tabular}{|c|c|c|}
\hline Question & Avg & Std \\
\hline Q1 & 3.86 & 1.17 \\
\hline Q2 & 3.70 & 1.10 \\
\hline Q3 & 3.96 & 1.11 \\
\hline Q4 & 4.21 & 1.15 \\
\hline Q5 & 3.66 & 1.20 \\
\hline Q6 & 3.83 & 1.12 \\
\hline Q7 & 2.39 & 1.12 \\
\hline
\end{tabular}

The average student response to Q8, regarding the student perceived best percentage of TL, is listed in Figure 6. The fouryear average is right at 50\%, indicating that students would like to have a 50/50 split of TL and PBL. One should keep in mind that in this reported hybrid PBL approach, the traditional lecturing is close to $80 \%$ in terms of the class time. Therefore, this suggests that the students would like to further reduce TL, and increase PBL in the course from approximately $20 \%$ to $50 \%$.

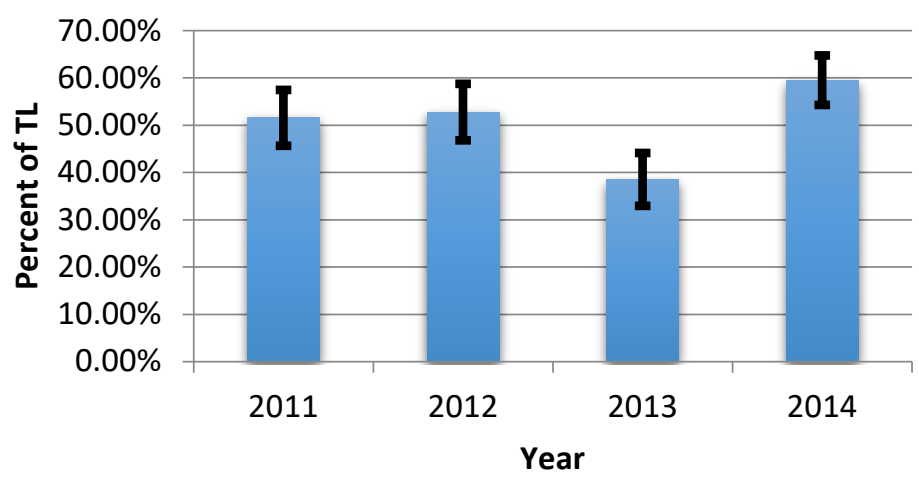

Figure 6. Averaged student response to the survey question Q8 “what would be the preferred percentage of TL”. The error bar marks the standard error.

\section{DISCUSSION AND CONCLUSION}

In the written comments section, students commented very positively toward the hybrid PBL approach implemented in this course. The following student comments are typical:

- " "PBL provides real-life learning to me and we should implement more PBL courses."

- " $\quad$ I should never forget what I learned here.” 
- "PBL is more practical and results in skills that can be applied when entering work."

- " $\quad$ PBL project taught me more than traditional plug and chug approach."

Overall, the students are much more enthusiastic toward the DIP course in comparison with the TL period. However, some students did feel that PBL was more difficult and more time consuming. For example, they responded:

- " "Time is a factor. Good balance between PBL and traditional lecture is needed.”

- " $\quad$ PBL is very intense and difficult. I need to spend more time to learn."

During the h-PBL study, one of the biggest complaints that the instructor received from the students was regarding team participation, i.e., some team member contributed significantly less than other members. For example, one students commented "It is difficult to deal with group members, especially when one member had a different priority." The instructor had multiple meetings with students concerning the issue with team work. While the instructor understood the frustration and might assist to form better teams and/or clarify the individual student assessment plan, deep involvement in the team management by the instructor was generally avoided. It should also be pointed out through that to learn how to function in a team is also part of the real world experience. The instructor feels that this is a part of the benefits of PBL for students to learn how to better function in a team environment.

However, even after repeated explanations and clarifications, there were always a few students who were confused about PBL. The instructor received feedback such as "I need more example problems for PBL." This suggests that some students felt more comfortable with the traditional lectures and the passive learning style.

In summary, an h-PBL approach was successfully developed and implemented in a digital image processing course. The student feedback confirms that the h-PBL approach does overall motivate student learning and stimulate student independent thinking. Even though most students felt that PBL was more difficulty and time-consuming, however, students predominantly agreed that they learned more through PBL. Implemented appropriately, PBL is a great tool to help the new generation of students. This paper provide a case study and can serve as a guidance for future implementations of h-PBL in engineering education. This study also points to several future research topics. For example, what would be the best time to introduce PBL to students and what is the best ratio of TL and PBL to maximize the educational benefits to the students?

\section{REFERENCES}

[1] Bond, D., and Feletti, G. E., [The Challenge of Problem-Base Learning], Kogan Page, London, (1997).

[2] Albanese, M., Ma, S., "Problem-based learning: a review of literature on its outcomes and implementation issues", Acad. Med., 68, 52-81 (1993).

[3] Carrio, M., Agell, L., Banos, J. Moyano, E., Larramona, P., and Perez, J., "Benefits of using a hybrid problem-based learning curriculum to improve long-term learning acquisition in undergraduate biology education”, FEMS Microbio. Letters, 363, 1-7 (2016).

[4] Selcuk, G., "The effect of problem based learning on pre-service teachers' achievement, approaches and attitudes towards learning physics”, Int. J. Phys. Sci., 5, 711-723 (2010).

[5] Yadav, A., Subedi, D., Lundeburg, M., and Bunting, C., "Problem-based learning: influence on students' learning in an electrical engineering course", J. Eng. Education, 100, 253- 280 (2011).

[6] Tan, S., and Shen, Z., "Hybrid problem-based learning in digital image processing: a case study", IEEE Trans. Edu., 61, 127-135 (2018).

[7] Duch, B. J., Groh, S. E., and Allen, D. E., [The Power of Problem-Based Learning], Stylus, Sterling, Virginia, (2001).

[8] ABET, "Criteria for Accrediting Engineering Programs, 2016-2017", https://www.abet.org/accreditation/accreditation-criteria/criteria-for-accrediting-engineering-programs-20162017/\#GC3. (20 October 2015).

[9] Srinivasan, V., Liu, H., and Halioua, M., "Automated phase-measuring profilometry of 3-D diffuse objects", Appl. Opt., 23, 3105-3108 (1984).

[10] Takeda, M. and Mutoh, K., "Fourier transform profilometry for the automatic measurement of 3-D object shapes", Appl. Opt., 22, 3977-3983 (1983). 
[11]Chen, W., Yang, H., Su, X., and Tan, S., "Error caused by sampling in Fourier transform profilometry," Opt. Eng., 36, 1029-1034 (1999).

[12] Guo, H., He, H., and Chen, M., "Gamma correction for digital fringe projection profilometry", Appl. Opt., 43, 29062914 (2004).

[13] Xu, W. and Cumming, I., "A region-growing algorithm for InSAR phase unwrapping," IEEE Trans. Geosci. Remote Sensing, 37, 124-134 (1999).

[14] Huntley, J. and Saldner, H., "Error-reduction methods for shape measurement by temporal phase unwrapping," J. Opt. Soc. Am. A, 14, 3188-3196 (1997).

[15] Su, X. and Tan, S., "Utilization of Cellular Automata Phase Unwrapping Method in 3-D Sensing,” Proc. SPIE, 2778, 479-480 (1996).

[16] Su, X. and Chen, W., "Reliability-guided phase unwrapping algorithm: a review”, Opt. \& Lasers in Eng., 42, 245-261 (2003).

[17]Likert, R., “A technique for the measurement of attitudes”, Archives of Psyc., 22, 5-55 (1932). 